\title{
CHARACTERIZATION OF ACTINIDES IN SIMULATED ALKALINE TANK WASTE SLUDGES AND LEACHATES
}

\author{
Project ID number 81940*
}

Principal Investigator:

Co-Investigator:

\author{
Kenneth L. Nash \\ Chemistry Department \\ Washington State University \\ Pullman, WA 99164 \\ (tel) 509-335-2654, (fax) 509-335-8867 \\ e-mail: knash@mail.wsu.edu) \\ Linfeng Rao \\ Lawrence Berkeley National Laboratory \\ (tel) 510-486-5427, (fax) 510-486-5596 \\ e-mail: LRao@lbl.gov
}

\begin{abstract}
* The Principal Investigator, K. L. Nash, moved from ANL to WSU in 2003. Currently, one postdoc and two summer undergraduate students are supported at WSU and one postdoc is supported at LBNL under this project.
\end{abstract}

\section{RESEARCH OBJECTIVES}

Treatment of underground tanks at Hanford with concentrated alkali to improve removal of wastelimiting components of sludges has proven less efficacious for $\mathrm{Al}$ and $\mathrm{Cr}$ removal than had been hoped. Hence, more aggressive treatments of sludges, including contact with oxidants targeting $\mathrm{Cr}(\mathrm{III})$, have been tested in a limited number of samples and found to enhance $\mathrm{Cr}$ removal. Unfortunately, treatments of sludge samples with oxidative alkaline leachates produce conditions under which normally insoluble actinide ions (e.g., $\mathrm{Am}^{3+}, \mathrm{Pu}^{4+}, \mathrm{Np}^{4+}$ ) can no longer be reliably assumed to remain in the sludge phase. Few experimental or meaningful theoretical studies of actinide chemistry in strongly alkaline, strongly oxidizing solutions have been completed. Extrapolation of acid phase thermodynamic data to these radically different conditions provides little reliable guidance for predicting actinide speciation in highly salted alkaline solutions. In this project, we are investigating the fundamental chemistry of actinides in sludge simulants and supernatants under representative oxidative leaching conditions. We are also examining the potential impact of acidic leaching with concurrent secondary separations to enhance Al removal. Our objective is to provide adequate insight into actinide behavior under these conditions to enable prudent decision making as tank waste treatment protocols develop. We expect to identify those components of sludges that are likely to be problematic in the application of oxidative leaching protocols.

\section{RESEARCH PROGRESS AND IMPLICATIONS}

This report summarizes work after 2 years of a 3-year project. On the basis of previous extensive studies on the leaching of actinides from simulated Hanford tank sludges, we have focused on the chemical behavior of plutonium and americium in oxidative alkaline leaching and the effect of organic complexants on the speciation of actinides in alkaline media.

Pu in Oxidative Alkaline Leaching. Our studies of oxidative alkaline leaching of the simulants indicated that low concentrations of permanganate in $3.0 \mathrm{M} \mathrm{NaOH}\left(10^{-5}\right.$ to $\left.10^{-4} \mathrm{M}\right)$ had minimal impact on the removal of $\mathrm{Cr}$ from sludge samples, that is, a similar amount of $\mathrm{Cr}$ was leached to that seen in 3.0 $\mathrm{M} \mathrm{NaOH}$ contacts.[1] At higher concentrations of permanganate, increasing amounts of chromate were seen in the leachate (Figure 1a). One possible implication of the existence of a threshold is that some disruption of the surface of the sludge simulant is needed to provide adequate access of the oxidant to the 


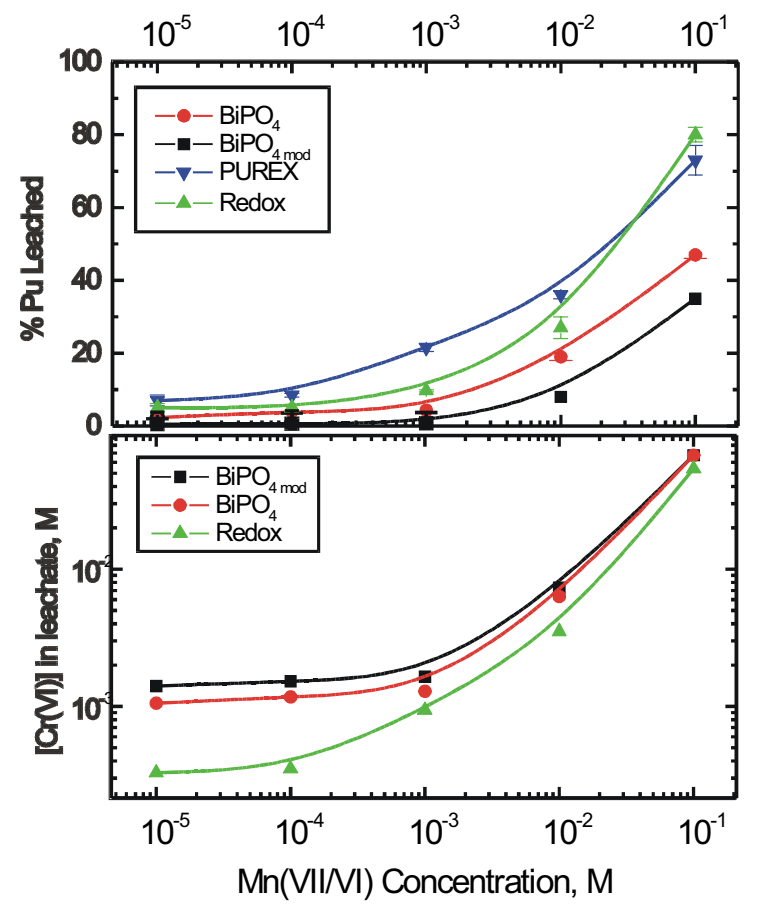

Figure 1. Permanganate effect on chromium and plutonium leaching from sludge simulants. reduced $\mathrm{Cr}(\mathrm{III})$. A concomitant increase in both $\mathrm{Pu}$ and Am content of the leachates was observed as the concentration of the oxidant increased (next paragraph). Near quantitative removal of $\mathrm{Cr}$ was noted, in general agreement with results on actual Hanford tank waste sludge samples.

The considerable disruption of the solid matrix that must occur during this oxidative leaching exposes not only reduced $\mathrm{Cr}$ species to solubilization, but can also expose oxidizable actinide ions to the same fate. Oxidative leaching of (sorbed) $\mathrm{Pu}$ from each sludge simulant with alkaline permanganate (3.0 M NaOH/ variable permanganate) resulted in significant increases in plutonium content of the leachate, as shown in Figure $1 \mathrm{~b}$. The concentration of $\mathrm{Pu}$ in the solution phase increased with the permanganate concentration. Similar concentrations of $\mathrm{Pu}$ were found in the leachate independent of the initial oxidation state of the $\mathrm{Pu}$. The parallel increase of $\mathrm{Pu}$ and $\mathrm{Cr}$ concentrations in the leachate are consistent with the suggestion that matrix disruption exposes actinides to potential mobilization by alkaline oxidants. The amount of $\mathrm{Pu}$ released from the sludges was notably lower from the $\mathrm{BiPO}_{4}$ sludge sample.

We also assessed the impact of permanganate oxidation of oxalate, citrate, glycolate, gluconate, and edta by contacting varying concentrations of each organic complexant with $0.1 \mathrm{M} \mathrm{KMnO}_{4}$ in $3.0 \mathrm{M}$ $\mathrm{NaOH}$. Radiotracer ${ }^{238} \mathrm{Pu}$ was present in all experiments as an indicator of $\mathrm{MnO}_{2}$ production. As the data in Figure 2 indicate, glycolate, gluconate and edta were oxidized (and $\mathrm{Pu}(\mathrm{VI})$ sorbed) while oxalate and citrate proved resistant to oxidation (and thus to $\mathrm{MnO}_{2}$ generation). Assuming that the removal of $\mathrm{Pu}$ from the supernatant solution was strictly through the agency of sorption onto $\mathrm{MnO}_{2}$, we noted that the amount of $\mathrm{Pu}$ removed from the solution phase correlated in a linear fashion with the amount of byproduct $\mathrm{MnO}_{2}$. This relationship persisted independent of which complexant was used to create the $\mathrm{MnO}_{2}$ sorbent. The residual organic degradation byproducts had no impact on $\mathrm{Pu}$ concentrations in the supernatant solution,

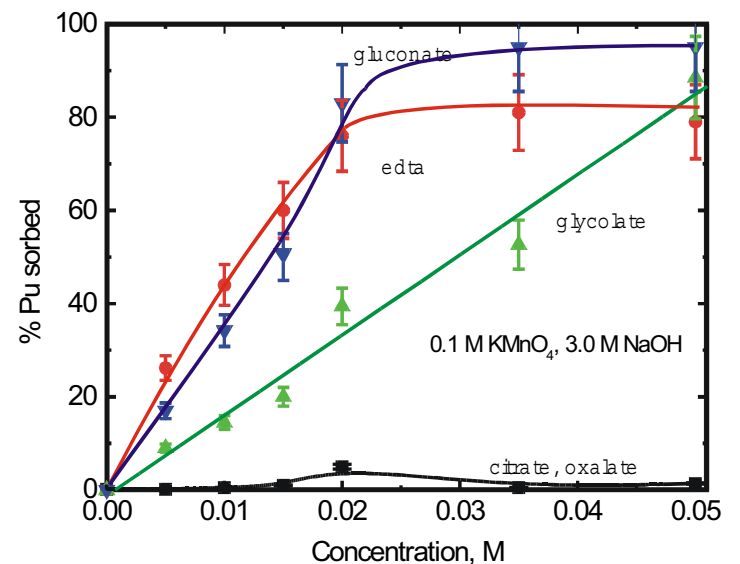

Figure 2. Plutonium sorbed from solution as a function of organic complexant oxidation by permanganate. that is, where present, sorption onto $\mathrm{MnO}_{2}$ controlled $\mathrm{Pu}$ concentrations in the solution phase. The resistance of citrate and oxalate to oxidation by permanganate is almost certainly related to the absence of a sufficiently reactive center (secondary alcohol or tertiary amine in glycolate, gluconate, and edta - oxalate and citrate have no similar functional groups). There have been no prior investigations of the oxidation of these organic complexants by alkaline permanganate. The practical implications of these observations are that appropriate organic materials could be used to consume excess oxidant during leaching. The concomitant production of an absorbant like $\mathrm{MnO}_{2}$ could sorb $\mathrm{Pu}$, thus potentially limiting the degree to which actinides might be accidentally mobilized from the sludge. These results also indicate that 
oxalate and citrate might become important complexants in such media.

Am in Oxidative Alkaline Leaching. To further assess the potential for coincidental actinide mobilization during oxidative leaching of tank waste sludges, we have examined the leaching of Amcontaining sludge samples by alkaline persulfate.[2] Though is it generally accepted that all oxidation states of Am above the trivalent are potent oxidants (that is, they are unstable), our preliminary investigations indicated some potential for enhanced Am dissolution by alkaline persulfate. In our studies, we observed that up to $60 \%$ of the Am sorbed onto our four sludge simulants was released to the solution phase upon treatment of the sludge samples with alkaline persulfate solutions. The maximum percentage of leached Am from each sludge simulant is shown to increase with increasing concentration of $\mathrm{NaOH}$ (Figure 3). Furthermore, the rates of oxidation/mobilization increased in the order $\mathrm{BiPO}_{4}<$ Redox $<$ Purex. Though one would not expect the oxidized Am to remain stable and in the supernatant in the long term, we did note that the maximum concentration in solution was maintained for at least 24 hours in most experiments. It is therefore conceivable that oxidative leaching could promote some removal of Am from actual sludge samples and maintain elevated concentrations long enough to become problematic during oxidative alkaline leaching to remove $\mathrm{Cr}$. We did not determine whether a similar result might be obtained for Am leaching with permanganate.

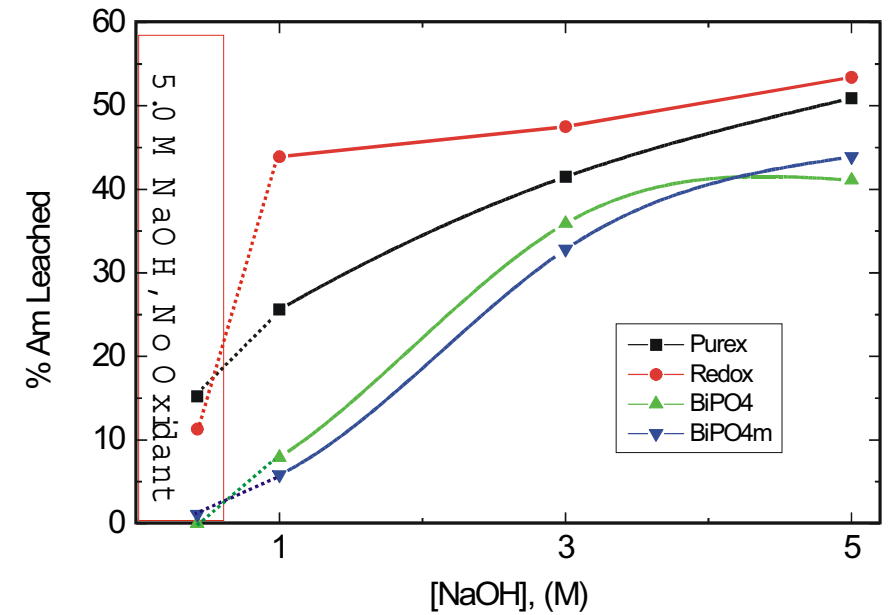

Figure 3. Maximum Am leached from sludge simulants by $0.1 \mathrm{M}$ persulfate as a function of $\mathrm{NaOH}$ concentration.

Speciation of Actinide ions in Alkaline Solutions. To continue the neptunium [3] and uranium [4] speciation work, we elected to investigate the chemistry of $\mathrm{Pu}(\mathrm{VI})$ in mixed hydroxycarbonate solutions. It is well known that the triscarbonato complex $\left(\mathrm{PuO}_{2}\left(\mathrm{CO}_{3}\right)_{3}{ }^{4-}\right)$ dominates the speciation of plutonium(VI) from about $\mathrm{pH} 6$ to 12 when carbonate/bicarbonate is present and that the centrosymmetric square bipyramidal tetrahydroxide $\left(\mathrm{PuO}_{2}(\mathrm{OH})_{4}{ }^{2-}\right)$ dominates $\mathrm{Pu}(\mathrm{VI})$ speciation in concentrated base solutions. We have completed an extended series of spectrophotometric titrations of $\mathrm{Pu}(\mathrm{VI})$ in mixed hydroxycarbonate solutions intermediate between these limits to determine whether any mixed hydroxycarbonate species might exist, as Neck et al noted for the corresponding $\mathrm{Np}(\mathrm{V})$ system. Representative spectra for the titration of $\mathrm{PuO}_{2}{ }^{2+}$ and of the tricarbonato complex with $\mathrm{NaOH}$ are shown in Figure 4. Though our analysis is not as yet complete of these complex data sets, we believe that we have identified two previously unreported mixed hydroxycarbonate complexes, $\mathrm{PuO}_{2} \mathrm{CO}_{3}(\mathrm{OH})_{2}{ }^{2-}$ and $\mathrm{PuO}_{2} \mathrm{CO}_{3}(\mathrm{OH})_{3}{ }^{3-}$ that contribute to $\mathrm{Pu}$ solubilization in the intermediate $\mathrm{pH}$ range wherein one might expect to see precipitation of $\mathrm{PuO}_{2}(\mathrm{OH})_{2}$. These assignments and the calculated equilibrium constants remain tentative at present.

HEDPA (hydroxyethane-1,1-diphosphonic acid) was employed as an exploratory leachant during the earliest stages of this investigation. We noted that it was capable of dissolving $\mathrm{MnO}_{2}$ from depleted sludge simulant samples and simultaneously partially or completely (depending on the element) dissolving actinides. Organophosphorus complexants of this type are also known for their ability to both descale corroded surfaces (that is, dissolve metal oxides) and to passivate metallic surfaces against corrosion.[5] To support possible utilization of this complexant for similar applications in tank waste cleanup, sludge dissolution, and residue stabilization, we have continued with the same methodology used for studies of uranyl oxalate/malonate to investigate the ligand/OH competition for HEDPA. The thermodynamics of actinide complexation by this chelating agent in acidic solutions has been described 

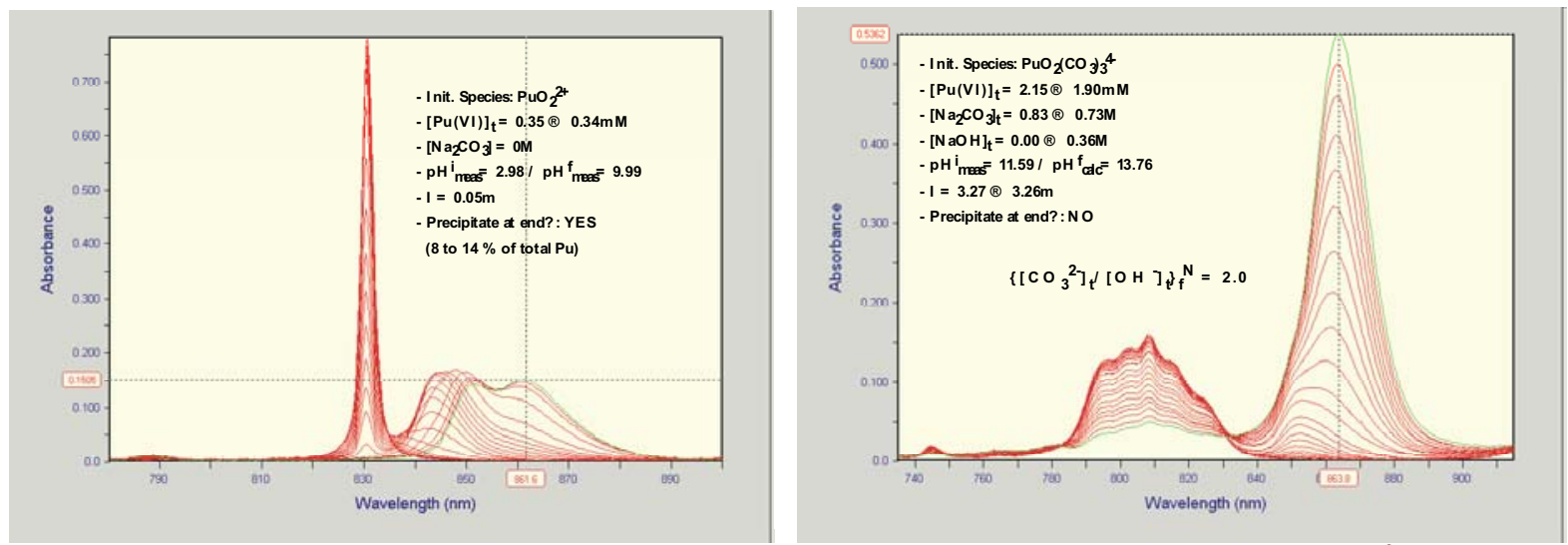

Figure 4. $\mathrm{Pu}(\mathrm{VI})$ spectra demonstrating the appearance of new complexed species as $\mathrm{PuO}_{2}{ }^{2+}$ aq or $\mathrm{PuO}_{2}\left(\mathrm{CO}_{3}\right)_{3}{ }^{4-}$ are titrated with $\mathrm{NaOH}$.

previously [6]. Continuing studies indicate more complex behavior characterizes the actinide complexes formed in this system at elevated $\mathrm{pH}$. Potentiometric $(\mathrm{pH})$ and spectrophotometric titrations, combined with ${ }^{31} \mathrm{P}$ NMR spectroscopy and EXAFS experiments have

confirmed the existence of multiple $\mathrm{M}_{m} \mathrm{H}_{h} \mathrm{~L}_{l}$ complexes across the $\mathrm{pH}$ 2-12 region, as shown in Figure 5. The complexes identified include $\mathrm{ML}, \mathrm{ML}_{2}$ and $\mathrm{M}_{2} \mathrm{~L}_{2}$ species with varying numbers of bound protons and hydroxide anions incorporated as well. Where they overlap, the equilibrium constants determined are generally consistent with previously reported data obtained by separations techniques in acidic solutions. We know from our previous investigations that diphosphonic acids are capable of maintaining $\mathrm{U}(\mathrm{VI})$ in solution over a wide range of $\mathrm{pH}$, We also have demonstrated that this complexant can be readily decomposed using Fenton-like chemistry to produce phosphate, $\mathrm{CO}_{2}$ and $\mathrm{H}_{2} \mathrm{O}$ or weakly complexing carboxylates.[7] Our planned extension of this work in the next funding cycle will build upon these results to explore further how reagents of this type can be employed to respond to aluminum dissolution and waste tank closure, two of the current greatest needs in tank remediation.
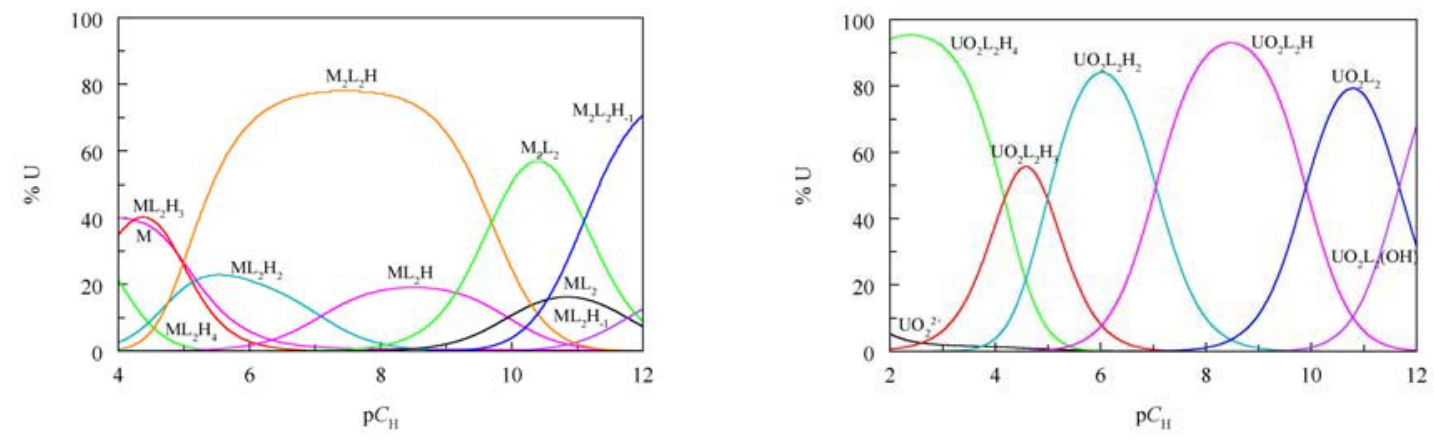

Figure 5. a) Formation of U(VI)/HEDPA complexes as a function of $\mathrm{p} C_{\mathrm{H}}$. $\mathrm{I}=1.0 \mathrm{M}$ tetramethylammonium chloride. $\mathrm{C}_{\mathrm{U}}=0.008 \mathrm{M}, \mathrm{C}_{\mathrm{L}}=0.016 \mathrm{M}, \mathrm{LH}_{4}$ stands for the ligand HEDPA, b) Formation of $\mathrm{U}(\mathrm{VI}) / \mathrm{HEDPA}$ complexes as a function of $\mathrm{p} C_{\mathrm{H}} . I=1.0 \mathrm{M}$ tetramethylammonium chloride. $C_{\mathrm{U}}=0.005 \mathrm{M}, C_{\mathrm{L}}=0.006 \mathrm{M}$. $\mathrm{LH}_{4}$ stands for the ligand HEDPA. 


\section{LITERATURE CITED}

1. K. L. Nash, M. Borkowski, M. Hancock, I. Laszak "Oxidative leaching of plutonium from simulated Hanford tank-waste sludges" Submitted for publication, EMSP Progress ACS Symposium Series Volume New York ACS Meeting September 2003.

2. W.A. Reed, A. Yu. Garnov, L. Rao , K. L. Nash, A. H. Bond "Oxidative Alkaline Leaching of Americium from Simulated High-Level Waste Sludges", Submitted for publication, Separation Science and Technology 2003.

3. A. V. Gelis, P. Vanysek, M. P. Jensen, K. L. Nash Radiochimica Acta 89, 565-571 (2001).

4. A. Yu. Garnov, L. Rao, K. L. Nash, A. H. Bond, Separation Science \& Technology 38, 359-374, (2003).

5. C. W. Drane, G. M. Smart, "Corrosion inhibiting compositions containing (1hydroxyethylidene)diphosphonic acid" Ger. Offen., 7 pp. CODEN: GWXXBX DE 2115427 19711028 Patent written in German (1971) (one of the earliest of many reports and patents on the subject) .

6. K. L. Nash, E. P. Horwitz, Inorganica Chimica Acta 169, 245-252 (1990); K. L. Nash, Radiochimica Acta 54, 171-179 (1991); K. L. Nash, Radiochimica Acta 61, 147-154 (1993); K. L. Nash, Journal of Alloys and Compounds 213/214 300-304 (1994); K. L. Nash, L. Rao, G. R. Choppin, Inorganic Chemistry 34, 2753 (1995).

7. E. H. Appelman, A. W. Jache, J. V.Muntean, Journal of Molecular Catalysis A: Chemical 106(3), 197-209, (1996); E. H. Appelman, A. W. Jache, J. V.Muntean, Industrial \& Engineering Chemistry Research 35(4),1480-2 (1996).

\section{PLANNED ACTIVITIES}

Four research topics as the reasonable path forward building on our previous results including; 1) to explore the efficacy of oxalic acid and gluconic acid as a leaching solution in which the $\mathrm{pH}$ of the leaching is varied between 1 and 14;2) to investigate the performance of mixtures of HEDPA and phytic acid on aluminum dissolution and actinide speciation across the $\mathrm{pH} 1$ to 14 range; 3) to continue the research on the cleanup of actinides from aluminum nitrate, a hypothetical end product of sludge dissolution; 4) to continue development of meaningful correlations of experimental results leading to discovery of "guiding principles" and a useful descriptive model for sludge performance during sludge scrubbing.

\section{INFORMATION ACCESS}

\section{Journal Articles}

W. R. Reed, A. Yu. Garnov, L. Rao, K. L. Nash, A. H. Bond; Oxidative Alkaline Leaching of Americium from Simulated High-Level Waste Sludges, submitted, Separation Science and Technology, (2004).

A. Yu. Garnov, L. Rao, K. L. Nash, A. H. Bond; Leaching of U(VI), Am(III) and Sr(II) from Simulated Tank Waste Sludges, Separation Science and Technology, 38 (2), 359-374 (2003).

K. L. Nash, A. V. Gelis, M. P. Jensen, A. H. Bond, J. C. Sullivan, L. Rao. A. Garnov; Actinides in Alkaline Media: Dissolution, Mineral Associations, and Speciation in Hanford Waste Tank Sludge Simulants, Nuclear Science and Technology, Supplement 3, 512-515 (2002).

A. V. Gelis, P. Vanysek, M. P. Jensen, K. L. Nash; Electrochemical and spectrophotometric investigations of neptunium in alkaline media, Radiochim. Acta, 89, 565-571 (2001). 
A. H. Bond, K. L. Nash, A. V. Gelis, J. C. Sullivan, M. P. Jensen, L. Rao; Plutonium Mobilization and Matrix Dissolution during Experimental Sludge Washing of Bismuth Phosphate, Redox, and Purex Waste Simulants. Separation Science and Technology, 36 (5 \& 6), 1241-1256 (2001).

A. H. Bond, K. L. Nash, A. V. Gelis, M. P. Jensen, J. C. Sullivan, L. Rao; Behavior of Actinide Ions during Sludge Washing of Alkaline Radioactive Wastes. in Material Research Society Symposium Proceedings: Scientific Basis for Nuclear Waste Management XXIII, 608, 595-600, 2000.

\section{Presentations}

A.H.Bond, K.L.Nash, A.V.Gelis, M.P.Jensen, J.C.Sullivan, L.Rao, A.Yu.Garnov; "Solid-State investigation of alkaline radioactive waste-sludge simulants", the 219th ACS National Meeting, San Francisco, CA, March 2000.

A.V.Gelis, K.L.Nash, G.Sandi, A.H.Bond, M.P.Jensen, J.C.Sullivan, L.Rao, A.Yu.Garnov; "Electrochemical investigations of An(V,VI,VII) in alkaline media", the 219th ACS National Meeting, San Francisco, CA, March 2000.

A.Yu.Garnov, L.Rao, K.L.Nash, A.V.Guelis, M.P.Jensen, J.C.Sullivan; "C-13 and O-17 NMR investigation of uranyl complexation with carboxylate ligands", LBNL-47087 Abs, the 221st ACS National Meeting, San Diego, CA, April 1-5, 2001.

A.Yu.Garnov, L.Rao, K.L.Nash, W.A.Reed; "Chemical behavior of U(VI), Am(III) and $\mathrm{Sr}(\mathrm{II})$ in the washing of HLW sludges", LBNL-50014 Abs, the 223rd ACS National Meeting, Orlando, FL, April 7$11,2002$.

W.A.Reed, A.Yu.Garnov, L.Rao, K.L.Nash; "Leaching of U(VI), Am(III) and Sr(II) from simulated waste tank sludges", LBNL-49989Abs, the $26^{\text {th }}$ Actinide Separations Conference, Berkeley, CA, June 36, 2002.

W.A.Reed, A.Yu.Garnov, L.Rao, K.L.Nash; "EXAFS and thermodynamic studies of uranyl complexes of HEDPA in neutral and alkaline solutions", LBNL-50030Abs, the 224th ACS National Meeting, Boston, MA, August 18-22, 2002.

W.A.Reed, A.Yu.Garnov, L.Rao, K.L.Nash; "Complexation of U(VI) with HEDPA in neutral and alkaline solutions", LBNL-52561Abs, the $27^{\text {th }}$ Actinide Separations Conference, Argonne, IL, June 9-12, 2003.

K.L.Nash, I.Laszak, M.Borkowski, M.Hancock, L.Rao, W.A.Reed; "Actinides in Hanford tank waste simulants: chemistry of selected species in oxidizing alkaline solutions", the 226th ACS National Meeting, New York, NY, September 7-11, 2003.

W.R.Reed, L.Rao, P.Zanonato, A.Yu.Garnov, K.Nash, A.H.Bond; "Thermodynamic studies of the complexation of uranyl(VI) with HEDPA in neutral and alkaline solutions", LBNL-54260 Abs, the 227th ACS National Meeting, Anaheim, CA, March, 2004. 